DOI: http://dx.doi.org/10.30684/etj.36.4A.1

\section{Ikram A. Saeed}

Civil Engineering Dept., Institute of Technology, Baghdad, Iraq.

ikrameng_amin@yahoo.com

\section{Riadh. Al-Mahaidi}

Swinburne University of Technology, Australia. ralmahaidi@swin.edu.au

\section{Tareq. S. Al-Attar}

Building and Construction Engineering Dept., University of Technology, Baghdad, Iraq.

\section{Basil. S. Al-Shathr}

Building and Construction Engineering Dept., University of Technology, Baghdad, Iraq.

Received on: 28/9/2016 Accepted on: 20/7/2017

\title{
Flexural Behavior of RC Beams Strengthened by NSM-CFRP Laminates or Bars
}

Abstract- The strengthening and enhancing the structures represents an important aspect in the construction industry due to the growing need to increase the tolerability of origin to a specific level and within the required rehabilitation and maintenance work. This paper assessed the performance and effectiveness of the Near Surface Mounted (NSM) strengthening technique for the reinforced concrete beams. Three $(140 \times 260 \times 2700 \mathrm{~mm})$ reinforced concrete beams were strengthened in flexure with NSM strengthening systems using Carbon Fiber Reinforced Polymer (CFRP) strips, bars, and cement-based adhesive as a binding materials. The flexural behaviour of the beams was evaluated by testing the specimens under three-point loading to failure. The structural performance, deflection, ductility, stiffness, and modes of failure of the tested beams are presented and discussed in this paper. The test results indicate that using NSM-CFRP strips and bars is practical and significantly improves the stiffness and increases the flexural capacity of reinforced concrete beams. The strength increments were 48, 42, and 15 percent recorded with CFRP bars, rough strips, and smooth strips respectively. The deflection of the strengthened beams was reduced by about 66, 48, and 58 percent for CFRP smooth strips, rough strips, and CFRP bars respectively, compared with the control beam due to the increased stiffness of the strengthened beams.

Keywords- CFRP; NSM; NSM CFRP flexural strengthening; reinforced concrete beams;

How to cite this article: I.A. Saeed, R. Al-Mahaidi, T.S. Al-Attar and B.S. Al-Shathr, "Flexural Behavior of RC Beams Strengthened by NSM-CFRP Laminates or Bars", Engineering and Technology Journal, Vol. 36, Part A, No. 4, pp. 358-367, 2018.

\section{Introduction}

The NSM FRP has been considered as an attractive method for increasing their flexural and shear strength $\mathrm{w}$ of RC members when strengthened with the ACI Committee 440 [1] are considering the design guidelines for this technique. The NSM Strengthening technique is about placing CFRP members, bars or strips, inside a pre-cut groove made within the concrete cover in the region of tensile stresses of the reinforced concrete member and then using a high strength epoxy adhesive or cementitious grout to bond them to the three sides of the groove using [2]. A variety of applications involved the NSM FRP technique and it showed several advantages over the external bonded FRP technique in strengthening concrete structures $[3,4]$.

The application of NSM has many advantages; one of the significant advantages is that it does not require any surface preparation work except grooving. when the NSM reinforcements is inside the grooves the concrete cover will protect them, which leads to strengthening the tensile zone of beams and slabs. As, a result, the harm resulting from fire, mechanical damages and other effects is significantly decreased. However, more initial costs might be required for NSM strengthening techniques compared to conventional externally bonded CFRP sheet application [5]. Beside the cost increase for groove cutting labor in NSM technique, the high cost of material and viscosity of adhesives in overhead situations can result in making the technique more expensive then externally bonded systems. The effect of grove size and the use of cementitious adhesives (or injection epoxies) rather than epoxy putty or paste adhesives could reduce the cost of the technique thus and additional research is needed. Furthermore, taking into account the superior characteristics of NSM strengthening, it becomes particularly interesting in seismic retrofit of RC column-beam joints providing either additional 
strength or durability when moving the failure zone from the column to the beam [6].

The NSM technique mostly involved the use epoxy resin as bonding material. On the other hand, cement paste has low viscosity which leads to make it hard to use in practice and that is why cement paste has not been used before with NSM technique. Hashimi and Al-Mahaidi [7] have developed a cement-based adhesive that is suitable to be used with NSM technique; significant bond properties were achieved by the addition of polymer to the mortar of the adhesive, which increased its viscosity also an excellent ductile behaviour of all specimens, was observed.

\section{Experimental Program}

\section{Specimen Dimensions and Details}

A total of four, simply supported concrete beams, $2700 \mathrm{~mm}$ in length, $140 \mathrm{~mm}$ wide, and $260 \mathrm{~mm}$ high were constructed and tested using a 5MN MTS machine under three-point loading up to failure at the Smart Structures Laboratory, Swinburne University of Technology using a displacementcontrolled rate of $2 \mathrm{~mm} / \mathrm{min}$. The beam had a $2300 \mathrm{~mm}$ effective span and a $900 \mathrm{~mm}$ shear span of. The bottom tension reinforcements were $3 \varnothing 12$ deformed steel bars, and $2 \varnothing 12$ at the top of the beam to hold the stirrups. To prevent any shear failure prior to flexural failure an adequate shear reinforcement was used with Ø10stirrups deformed steel bar were distributed along the beam every $125 \mathrm{~mm}$ center-to-center. Beam dimensions and reinforcement details are shown in Figure 1.
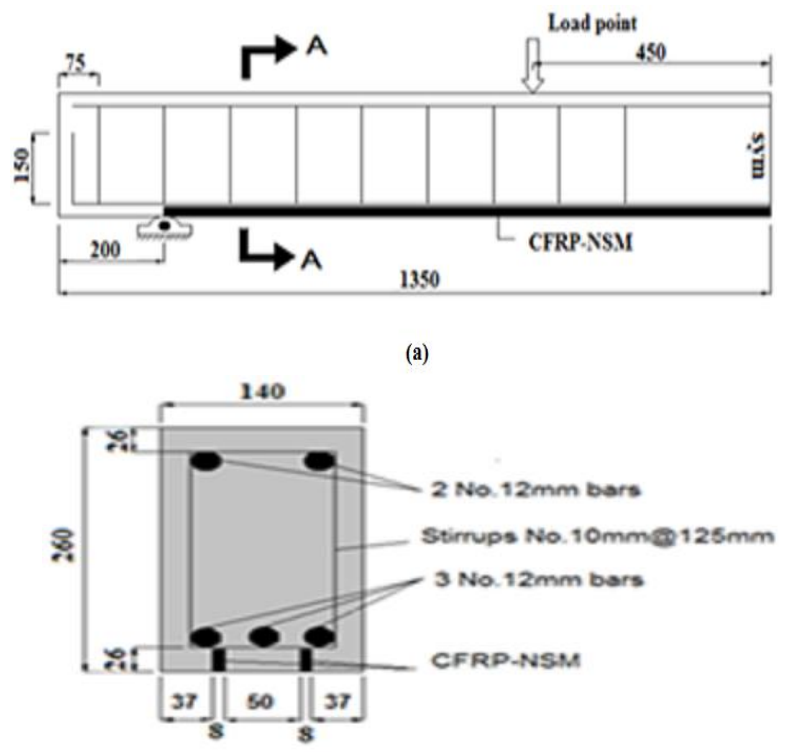

(b)

Figure 1: Beam dimensions and reinforcement details: a) Elevation, b) Section A-A

\section{Materials}

\section{Concrete}

The concrete material was supplied by a ready-mixed concrete local supplier (Hanson-Heidelberg Cement Group) in order to minimize the variations of all constituents and to achieve good quality control. Batch proportion of concrete shown in Table 1. To specify the properties of concrete used in the reinforced concrete beam specimens, an average of three $(100 x 200) \mathrm{mm}$ cylinders were tested for each property. Table 2 lists the properties of the concrete and cement-based adhesive cylinders specimens.

\section{Cement-Based Adhesive}

Cement-based adhesive was chosen as a binder with CFRP in the strengthening system. For strengthening beams with NSM-CFRP, a cement-based adhesive consisting of cement, micro cement, silica fume, silica filler primer, super-plasticizer and water was used. The mix design is provided in Table 3. Mortar cylinders were cast, $50 \mathrm{~mm}$ in diameter and $100 \mathrm{~mm}$ in height.

Table 1: Batch proportion of concrete per one cubic meter

\begin{tabular}{ll}
\hline \hline Mix parameter & Quantity \\
\hline Grade (MPa) & 32 \\
CA Goliath Type GP Cement ( $\mathrm{kg})$ & 331 \\
ICL GGBFS (Slag) (kg) & 99 \\
Hanson Kilmore14mm aggregate $(\mathrm{kg})$ & 1150 \\
Hanson Yannathan sand (SSD) $(\mathrm{kg})$ & 775 \\
Tap Water (Liter) & 180 \\
Nominal slump (mm) & 80 \\
\hline
\end{tabular}

Table 2: Properties of the tested concrete cylinders

\begin{tabular}{llll}
\hline \hline & $\begin{array}{l}\text { Compressive } \\
\text { strength } \\
(\mathrm{MPa}), \text { AS }\end{array}$ & $\begin{array}{l}\text { Tensile } \\
\text { strength } \\
(\mathrm{MPa}), \text { AS }\end{array}$ & $\begin{array}{l}\text { Modulus of } \\
\text { Elasticity } \\
(\mathrm{GPa})\end{array}$ \\
& $1012.9[8]$ & 1012.10 [9] & \\
\hline $\begin{array}{l}\text { Concrete } \\
\begin{array}{l}\text { Cement-based } \\
\text { adhesive }\end{array}\end{array}$ & 32.8 & 4.12 & 31900 \\
\hline
\end{tabular}

Table 3: Mix proportions of cement-based adhesive

\begin{tabular}{ll}
\hline \hline Material & Content, g \\
\hline $\begin{array}{l}\text { Ordinary Portland cement conforming } \\
\text { to AS 3972 [10] }\end{array}$ & 674.3 \\
$\begin{array}{l}\text { Microcement, specific surface area } \geq \\
1200 \mathrm{~m} 2 / \mathrm{kg}\end{array}$ & 168.6 \\
$\begin{array}{l}\text { Silica fume meeting the requirements } \\
\text { of ASTM C1240 [11] }\end{array}$ & 84.3 \\
$\begin{array}{l}\text { Filler (Silica 200G), fineness 8000 } \\
\mathrm{cm}^{2} / \mathrm{g}\end{array}$ & 716.5 \\
$\begin{array}{l}\text { Primer MBrace Primer(A+B) } \\
\text { manufactured by BASF (Australia) }\end{array}$ & 88.6 \\
$\begin{array}{l}\text { Superplasticizer } \\
\text { (Sika Viscocrete 5-500) }\end{array}$ & 16.9 \\
Water & 354 \\
\hline
\end{tabular}




\section{Steel reinforcement}

Tensile tests in accordance with AS1391 (2007) [12] were carried out to determine the properties of the steel bars. The properties of the tested steel bars are shown in Table 4.

\section{Carbon Fiber Reinforced Polymer, CFRP}

CFRP rough bar and laminate (rough and smooth) were manufactured by BASF Construction Chemicals Australia. The mechanical properties were determined using testing procedures in accordance with $\mathrm{ACI}$ 440.3R-04 [13] and Table 5 is showing the results.

\section{Test Specimens and Designation}

To assess the flexural strength improvement resulting from the NSM reinforcements, one beam was tested without strengthening (C) to serve as the control specimen for comparison purposes. Three beams (SL, $\mathrm{RL}$, and $\mathrm{RB}$ ) were strengthened using NSM CFRP smooth strips, rough strips, and rough bars, respectively. Table 6 shows a summary of these beams. The embedment lengths of all the NSM FRP bars and strips were kept constant in all beams at $2300 \mathrm{~mm}$. Moreover, the same area, for all FRP reinforcement was kept constant to ensure the same area of fiber in each beam. The deflection at mid span was monitored on both sides of the beam by using two linear differential transducers (LDTs). Readings from LDTs were recorded during testing every second using a data acquisition system connected to a computer. To measure the strain in the FRP reinforcement during testing, four gauges were installed on each CFRP (strip and bars) and each beam had two strips making a total of 8 gauges for each beam. The strain gauge layout is shown in Figure 2.

Table 4: Properties of tested steel bars

\begin{tabular}{lllll}
\hline \hline $\begin{array}{l}\text { Nominal } \\
\text { Diameter } \\
(\mathbf{m m})\end{array}$ & $\begin{array}{l}\text { Yield } \\
\text { strength } \\
(\mathbf{M P a})\end{array}$ & $\begin{array}{l}\text { Ultimate } \\
\text { strength } \\
(\mathbf{M P a})\end{array}$ & $\begin{array}{l}\text { Ultimate } \\
\text { strain }\end{array}$ & $\begin{array}{l}\text { Modulus of } \\
\text { Elasticity } \\
(\mathbf{G P a})\end{array}$ \\
\hline 12 & 550 & 680 & 0.125 & 214 \\
10 & 530 & 660 & 0.12 & 208 \\
\hline
\end{tabular}

Table 5: Properties of CFRP laminates and bars

\begin{tabular}{llll}
\hline \hline Property & $\begin{array}{l}\text { CFRP } \\
\text { smooth } \\
\text { surface } \\
\text { laminate }\end{array}$ & $\begin{array}{l}\text { CFRP rough } \\
\text { surface } \\
\text { laminate }\end{array}$ & $\begin{array}{l}\text { Rough } \\
\text { CFRP } \\
\text { bar }\end{array}$ \\
\hline $\begin{array}{l}\text { Tensile } \\
\text { strength } \\
\text { (MPa) }\end{array}$ & 2545 & 3697 & 2300 \\
$\begin{array}{l}\text { Modulus of } \\
\text { elasticity } \\
\text { (GPa) }\end{array}$ & 205 & 212 & 161 \\
$\begin{array}{l}\text { Ultimate } \\
\text { strain \% }\end{array}$ & 1.3 & 1.4 & 1.26 \\
\hline
\end{tabular}

\section{Installation of the FRP Reinforcements}

The NSM CFRP rebar and strips installation started with making the grooves, two longitudinal grooves on the concrete tension face of each beam except the control beam were carefully cut to 2300 $\pm 10 \mathrm{~mm}$ lengths using a tuck-point grinder in conjunction with a diamond concrete blade. Two different groove sizes were used in the current experimental work, $8 \mathrm{~mm}$ width $\mathrm{x} 24 \mathrm{~mm}$ depth for CFRP laminate and $12 \mathrm{~mm}$ width $\mathrm{x} 20 \mathrm{~mm}$ depth for CFRP bars, as recommended by ACI 440.2R08 [1]. First, the beams were placed upside down; the grooves were wetted before inserting the adhesive. The strengthening procedure was carried out as follows:

i. A layer of cement-based adhesive was placed on the fibre.

ii. The groove was filled to half its depth with cement-based adhesive and the CFRP strip/ bar was then placed in the groove and slightly pressed. iii. The positioning of CFRP strip/ bar at the center and distributing the adhesive layer equally between the fibre and the surface of the groove were carefully considered.

iv. After positioning the CFRP strip, the installation was completed by adding more cement-based adhesive to fully fill the grooves and the surface was levelled.

$\mathrm{v}$. The beams were covered with moist burlap and plastic sheets for 7 days.

Table 6: Beam test variables

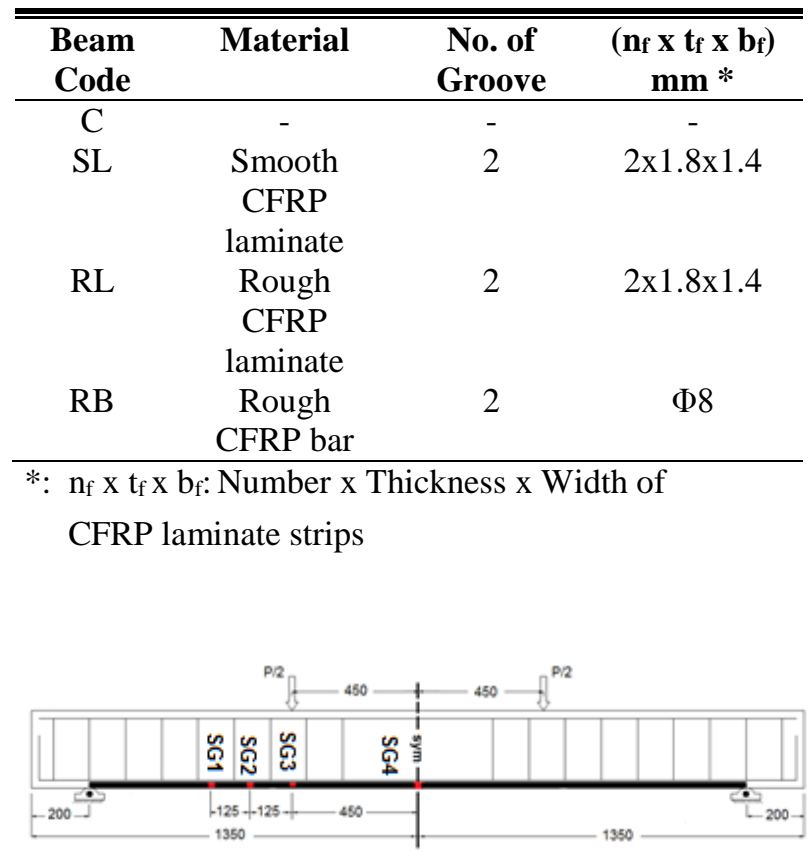

Figure 2: Strain gauge layout 


\section{Test Results and Discussion}

\section{Load-Deflection Curve}

Table 7 shows the results of the tested beams in terms of ultimate load Pu, cracking load Pcr,

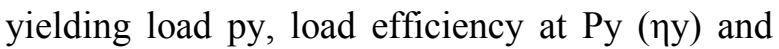
load efficiency at $\mathrm{Pu}(\eta \mathrm{u}) \%$, following the procedure proposed by Sharaky et al. [14], deflection, and mode of failure.

\section{Control beam, $C$}

The load-deflection curve for the control beam, C, is shown in Figure 3. It can be seen that the beam exhibit a linear response until cracking occurs in the concrete in the initial stages at the load of 56 $\mathrm{kN}$ approximately. The mid-span deflection then increases at a higher rate until reaching the maximum $68.8 \mathrm{~mm}$ due to decreasing stiffness resulting from cracking in the concrete beam. At this stage, the stresses in steel increase at a faster rate until the steel rebars yield. The ultimate capacity reaches its peak once the steel rebar enters the yielding plateau. The ultimate failure load was $99.8 \mathrm{kN}$. The flexural cracks spread upward an enlarged with load increment, as shown in Figure 4. The failure mode was concrete crushing after the yielding of steel, which is a typical failure mode in unstrengthened RC beams.

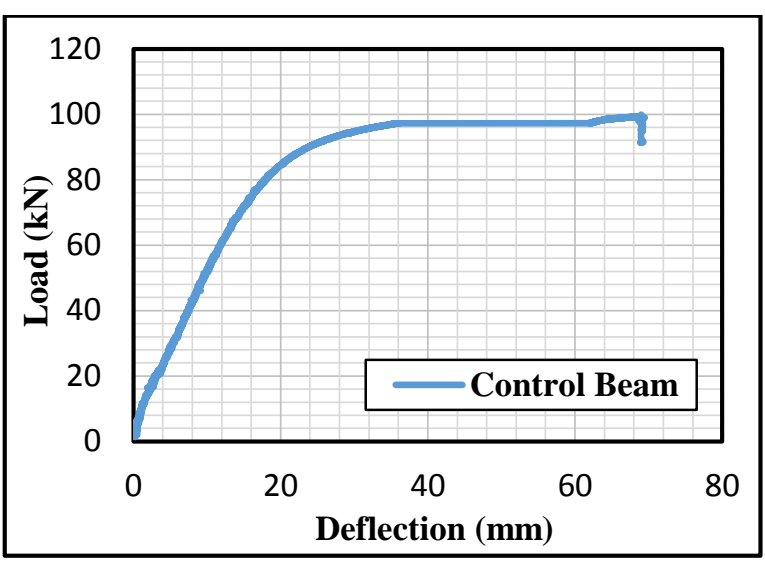

Figure 3: Load-deflection curve for control beam

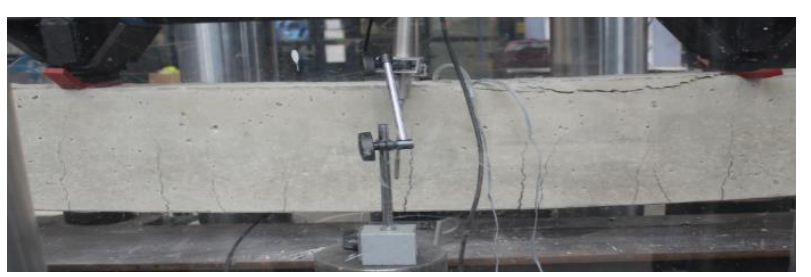

(a)

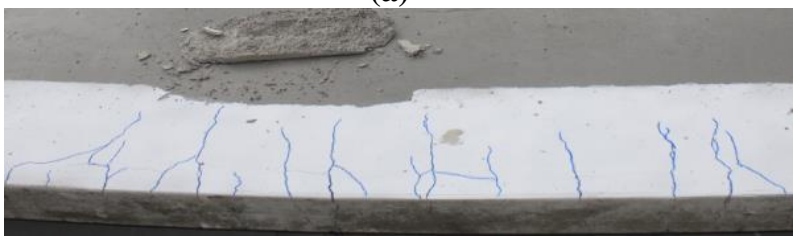

(b)

Figure 4: Failure mode for control beam: a) Concrete crushing, b) Crack pattern

Table 7: Results of the tested beams

\begin{tabular}{|c|c|c|c|c|c|c|c|c|}
\hline $\begin{array}{l}\text { Beam } \\
\text { Code }\end{array}$ & $\begin{array}{l}\mathbf{P}_{\mathbf{c r}} \\
(\mathbf{k N})\end{array}$ & $\begin{array}{l}\mathbf{P}_{\mathbf{y}} \\
(\mathbf{k N})\end{array}$ & $\begin{array}{l}\mathbf{P}_{\mathbf{u}} \\
(\mathbf{k N})\end{array}$ & $\begin{array}{l}\eta_{\mathbf{y}} \\
(\%)\end{array}$ & $\begin{array}{l}\eta_{u} \\
(\%)\end{array}$ & $\begin{array}{l}\delta_{\mathrm{cr}} \\
(\mathbf{m m})\end{array}$ & $\begin{array}{l}\delta_{\mathbf{u}} \\
(\mathbf{m m})\end{array}$ & Failure mode \\
\hline $\mathbf{C}$ & 56.4 & 79.15 & 99.8 & - & - & 10.8 & 68.8 & $\begin{array}{l}\text { Concrete crushing after yielding of the steel tension } \\
\text { reinforcing }\end{array}$ \\
\hline SL & 60.9 & 93.9 & 114.5 & 18.54 & 15.5 & 7.8 & 35.7 & $\begin{array}{l}\text { Concrete crushing after debonding between the fiber } \\
\text { and adhesive }\end{array}$ \\
\hline $\mathbf{R L}$ & 68.4 & 127.93 & 140.9 & 61.62 & 42.1 & 8.1 & 22.9 & $\begin{array}{l}\text { Concrete crushing after debonding between the fiber } \\
\text { and adhesive }\end{array}$ \\
\hline $\mathbf{R B}$ & 70.5 & 120.91 & 146.9 & 52.7 & 48.2 & 10.6 & 29 & $\begin{array}{l}\text { Concrete crushing after debonding between the fiber } \\
\text { and adhesive }\end{array}$ \\
\hline
\end{tabular}

\section{Strengthened Beam with Smooth Laminate, SL}

Figure 5 illustrate the load-deflection scheme of the SL beam. The strength showed slight increases over that of the reference beam, with an ultimate load of $114.5 \mathrm{kN}$. The increment was approximately $15 \%$. The beam showed linear loaddeflection behaviour until steel yielding, followed by nonlinear performance up to failure. After the first crack that started at a load of $61 \mathrm{kN}$ and typically formed at mid-span, the load-deflection behaviour was influenced by the formation of more flexural cracks formed at the load points and the excessive flexural cracks that formed between the midspan and the internal supports. Steel yielding started the failure mode, followed by concrete crushing. Subsequently, debonding occurred within the fiber and adhesive through the interfacial zone accompanied by cracks along the adhesive. Figures 6 and 7 present the two failure modes. 


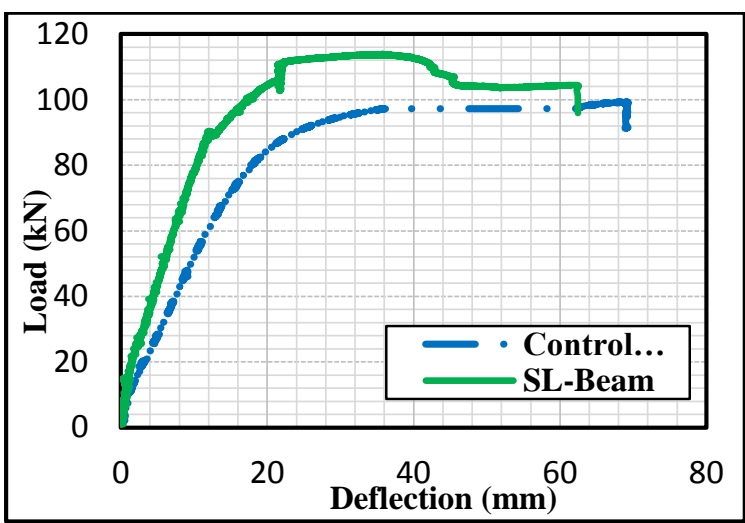

Figure 5: Load-deflection curve for SL beam

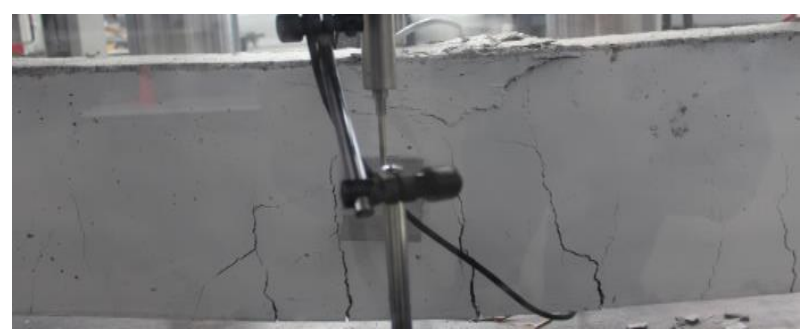

Figure 6: concrete crushing in SL beam

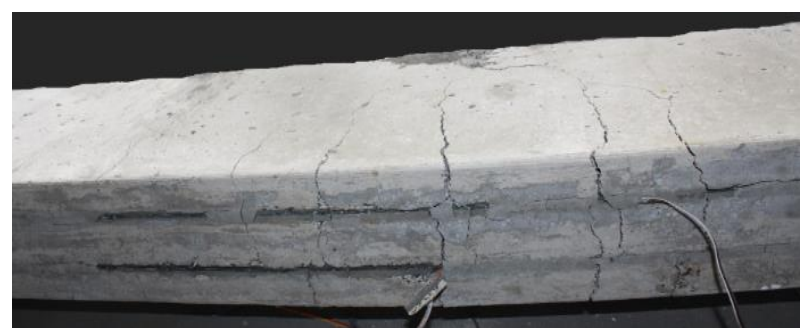

Figure 7: Failure mode with debonding of fiber in SL beam

\section{Strengthened Beam with Rough Laminate, $R L$}

The load versus deflection curve for the RL beam shown in Figure 8. The rough surface laminates strips enhanced the flexural strength of the beam more than the smooth surface laminate strips did. This can be attributed to the nature of the surface of the CFRP strips, as rough surface CFRP strips provided more bond than the smooth surface CFRP strips. The increases in ultimate load was approximately 24 and 42 percent greater than those of SL and C beams respectively. The ultimate load was $140.9 \mathrm{kN}$. Initial cracks started on RL beam at load of $68 \mathrm{kN}$, which was higher than those of the SL and reference beams. The NSM-CFRP rough surfaces beam exhibited higher yield load, approximately $36 \%$ and $61 \%$ greater than those of the SL beam and the reference beam, respectively. Moreover, the stiffness increased significantly over the reference beam within the post-cracking stage, and was more noticeable than that achieved by the SL beam. After debonding of the NSM-
CFRP bar, the load dropped, similar to the control beam C. This load represents the residual frictional stresses between the fibre and the adhesive. As shown in Figures 9 and 10, the RL beams failed by concrete crushing at mid-span followed by adhesive-concrete interface debonding and centralize splitting of the cement-based adhesive.

\section{Strengthened Beam with Rough CFRP Bar, RB}

Beam RB (i.e. the beam strengthened with NSMCFRP bars) the highest strength increment was shown with ultimate load of $146.9 \mathrm{kN}$. Higher yield load, approximately $29 \%$ and $52 \%$ over the SL beam and the reference beam respectively but slightly lower than that of the RL beam of about $5.8 \%$. Initial cracks started at load of $70 \mathrm{kN}$ with further increases in loading propagation of the cracks took place. Figure 11 shows approximately linear behavior with regard to concrete, cracking and steel yielding phases. First, before the cracking phase. Similar to the control beam, the strengthened beam exhibited linear-elastic behaviour like. The NSM-CFRP bars had little effect on the cracks formed at mid-span of the beam. In the second phase, between cracking and steel yielding, the NSM-CFRP bars increased the yielding load and the stiffness of the beam when compared with the control beam. In this phase, the load increased about 48 percent of the reference beam, $C$. The third phase covered the time after steel yielding until failure. This phase showed nonlinear behavior; higher range increase in deflection was shown than in the previous phase. It's obvious from the curve that there are two drops in the load after the ultimate value but again ascending up till failure. However, fiber still provided friction stress and the CFRP bars still have the ability to carry out loads higher than the unstrengthened beam did with more deflection rate, and this lead to make the beam showing better performance even at failure. The failure mode was debonding of the bar at the adhesive-bar interface. Severe cracking occurred in the adhesive layer (refer to Figures 12 and 13).Major cracks formed between the mid-span and the load point and failure occurred after the bond between the FRP bars and the surrounding adhesive was lost associated with cracking and peeling of the adhesive at the surface. The failure of the CFRP was localized along the groove, which indicated the existence of an effective failure zone in the vicinity of the installed NSM-CFRP bars. Post failure examination of the samples showed that on the failure bond plane, large portions of the grout adhesive bonded throughout some sections, while other sections of the CFRP bar did not show any 
grout attached after failure. The RB beam gave the best results with respect to the ultimate load for this group.

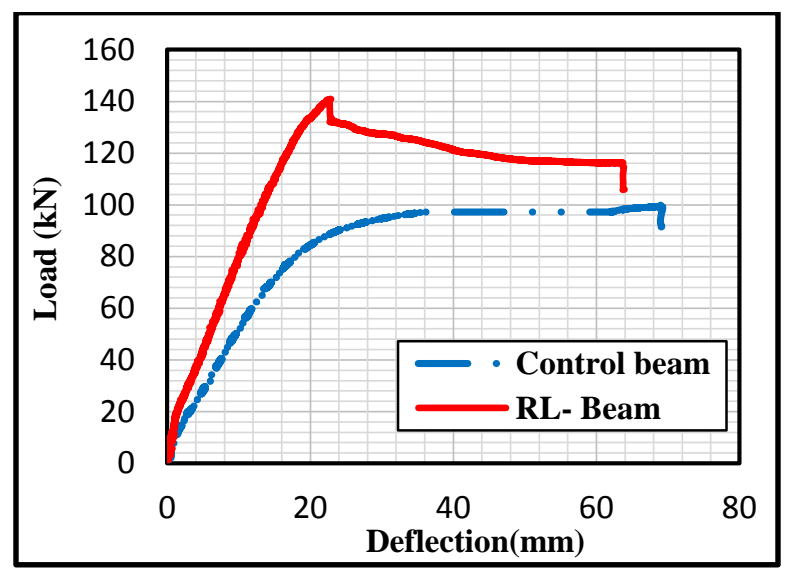

Figure 8: Load-deflection curve for RL beam

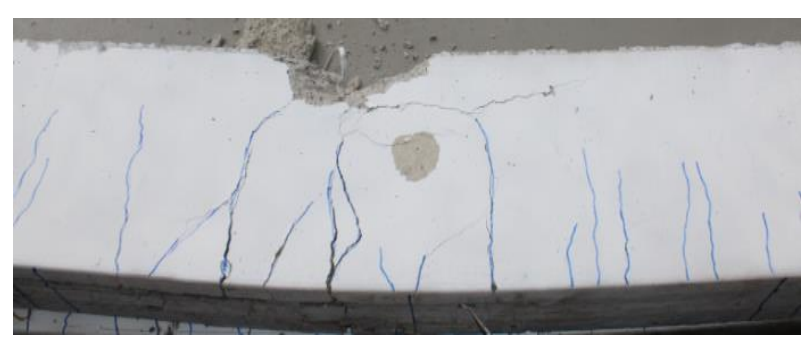

Figure 9: Concrete crushing in RL beam

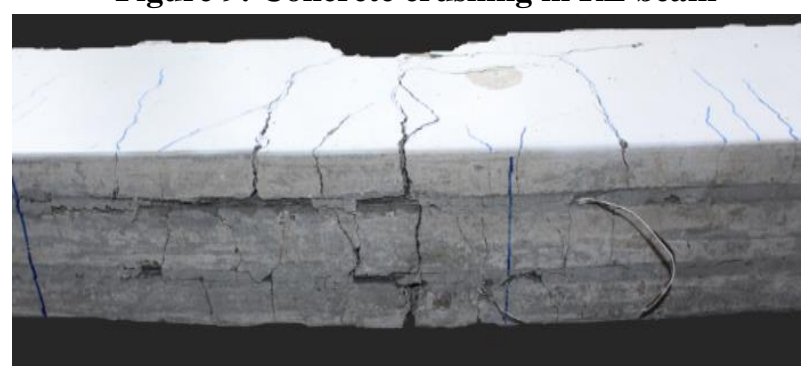

Figure 10: Failure mode with debonding of fiber in RL beam

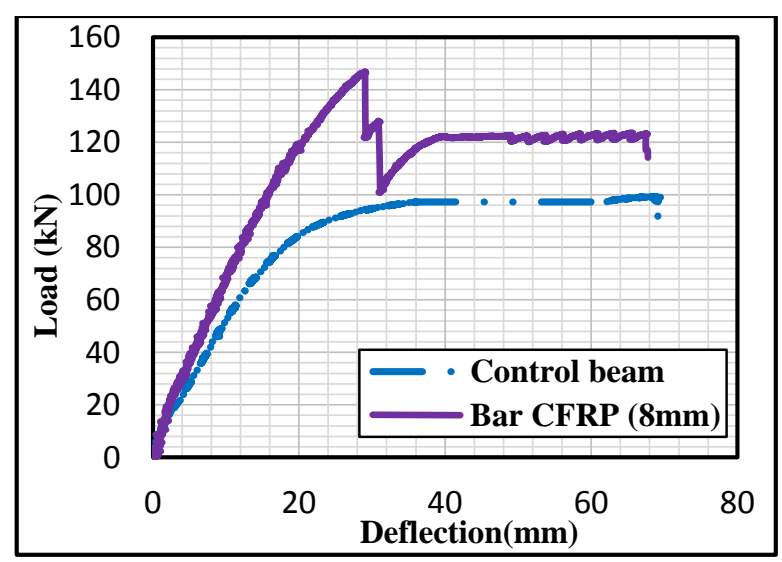

Figure 11: Load deflection curve of RB beam

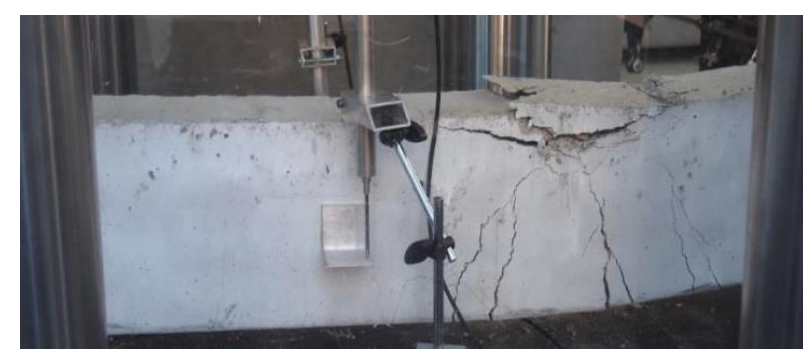

Figure 12: concrete crushing in RB beam

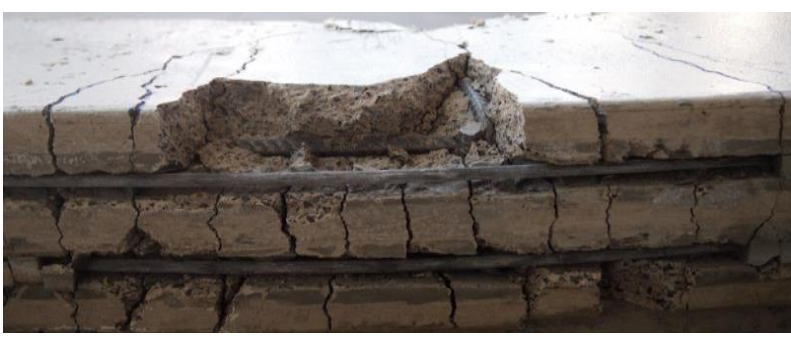

Figure 13: debonding of CFRP bars

The results can be summarized as follows:

Beams started cracking at load levels of 56.4, 60.9, 68.4, and $70.5 \mathrm{kN}$ for control beam $\mathrm{C}$, strengthened beams SL, RL, and RB, respectively. Despite the higher failure loads are for the strengthened beams, their crack patterns at ultimate load are very similar to the control beam. The favourable influence of FRP on the cracking behaviour is in consistent with the increased stiffness in the cracked state of the strengthened beams. The recorded load-deflection curve clearly show that the three beams strengthened with NSM CFRP showed significant increases in strength compared to the unstrengthened control beam and this is clarified in Figure 14. The strength increases were 48,42 , and $15 \%$ recorded with the RB, RL, and SL beams, respectively.

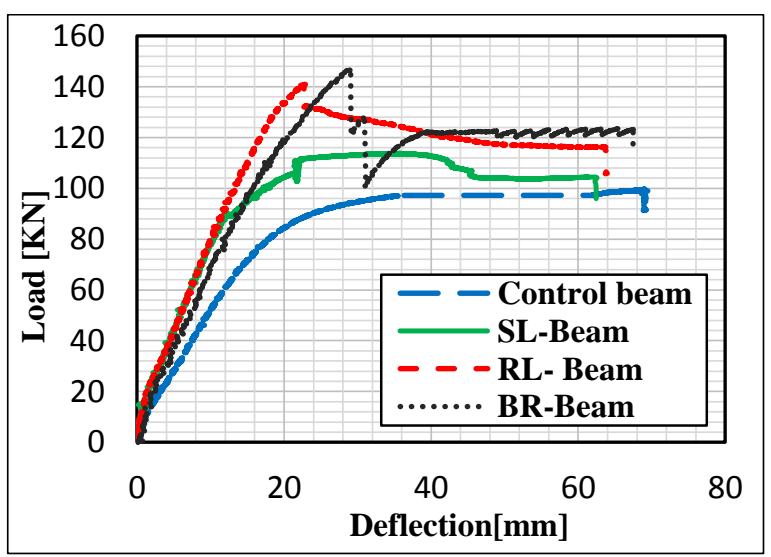

Figure 14: Load-deflection curves for all RC beams 


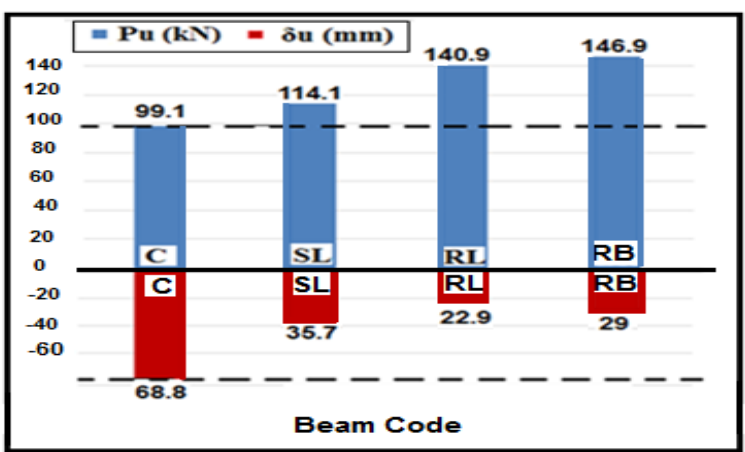

Figure 15: Comparison of the load capacity and the corresponding deflection of the beams

In spite of the different CFRP configurations, all strengthened beams were well maintained the composite action between the original beam and the NSM-CFRP ones, since the failure occurred through crushing of the top concrete after the yielding of internal steel bars. This result is agree with the finding of De Lorenzis and Teng [15]. Figure 15 illustrates comparison of the maximum load $(\mathrm{Pu})$ and the corresponding deflection of the strengthened beams. The strengthened beams experienced higher load capacities than the control beam, whereas the deflection was less. The deflection of the strengthened beams was reduced by a maximum of about $48 \%, 66 \%$ and $58 \%$ for the SL, RL, and RB strengthened beams respectively, compared with the control beam due to the increased stiffness of the strengthened beams.

\section{Strain Distribution along the CFRPs:}

The strain distributions along CFRPs are plotted at different load levels in Figures 16 to 18 for the SL, $\mathrm{RL}$, and BR beams respectively. In each specimen, the strain value increasing rate (the slope of strain vs. load curve) was very small at lower loads. The concrete did not crack within this load range and the CFRP did not contribute very much. The section almost worked as an ordinary reinforced concrete section. When the concrete cracked at around (61-70) kN, the CFRP started contributing effectively and the slope of strain vs. load curve changed. As shown in Figure 16, the peak recorded strain of the SL beam in the CFRP strips which occurred at the mid-span was 6105 microstrain, since the failure in the fiber occurred under this point. From Figure 17, the RL beam showed the maximum strain value of 7789 microstrain. The peak occurred at the center of the beam. This strain value is very close to that recorded under the load point, especially at loads of 120 and $140 \mathrm{kN}$, as the cracks in the high moment region became wider and deeper than when loads are lower. This means that the CFRP strips in this region act as a tie supported by the rest of the bond length located in the shear span. The peak recorded strain value of CFRP in the BR beam was 7098 microstrain under the load point. This value is lower than the corresponding value of that in beam RL because the failure point occurred at mid-distance between the beam center and the load point, and the maximum value was not recorded at the failure point. With reference to Figure 4.18, SG4: strain gauge at the centre of the beam, SG3: is the strain gauge at $450 \mathrm{~mm}$ distance from SG4, SG2: is the strain gauge at $125 \mathrm{~mm}$ distance from SG3, and $\mathrm{SG} 1$ : is the strain gauge at $125 \mathrm{~mm}$ distance from SG2, as illustrated previously in Figure 2.

\section{Stiffness and Ductility}

Figure 19 shows the relative stiffness of the strengthened beams compared to that of the control beam (C), using Equation 1 [14].

Stiffness $\%=\frac{\delta c-\delta s t r .}{\delta c} \times 100$

where $\delta \mathrm{c}$ and $\delta$ str are the deflection of the control and strengthened beams, respectively.

It can be seen from the figure above that all strengthened beams exhibited considerably stiffer post-cracking behaviour than the control beam. However, the cracks were spaced more evenly and closer compared to those in the control beams. The stiffness of the strengthened beams increased by an amount that depended mainly on the surface preparation of CFRP and the bonded area of CFRP material. Moreover, when the tensile strength and modulus of CFRP increased, so did the stiffness of the strengthened beams. Beams strengthened with CFRP rough surface strips (RL) experienced higher stiffness than those of specimens strengthened with smooth surface strips (SL) and with CFRP bar (BR) in post cracking stage, while the SL beam show higher stiffness at yielding stage than the RL and BR beams. Increase in stiffness caused lower curvatures resulting in deflection reduction. From the viewpoint of ductility, although CFRP has high strength, it is very brittle. When loaded in tension, CFRP exhibits a linear stress-strain behaviour up to failure without exhibiting any indication of impending failure. As CFRP behave differently from steel, it consequently suffers from a significant loss in beam ductility, particularly when CFRP is used for the flexural strengthening of RC beams.

When applied to RC members, the term ductility implies the ability to sustain significant inelastic deformation prior to collapse. The ductility index in this study was obtained based on deflection computation [16] expressed as follows: 


$$
\begin{aligned}
& \mu \Delta u=\frac{\Delta u}{\Delta y} \\
& \mu \Delta f=\frac{\Delta f}{\Delta y}
\end{aligned}
$$

where $\mu \Delta u$ and $\mu \Delta f$ is the displacement ductility indices at ultimate load and load at failure, respectively. $\Delta u, \Delta f, \Delta y$ is the mid span deflections at ultimate load, failure load and yield load respectively. Table 7 shows the ductility ratios of the tested beams.

The ductility of the RC beam specimens decreased with increased strengthening reinforcement [17]. This was due to the non-ductile performance of CFRP with the linear stress-strain relationship and the comparatively brittle failure modes owing to the separation of the strengthening reinforcement from the concrete. It was observed that the ductility indices of all strengthened beams were lower than that of the control specimen at both ultimate and failure loads. However, the specimens strengthened with NSM-CFRP strips had slightly higher ductility indices than the beam strengthened with NSM-CFRP bars.

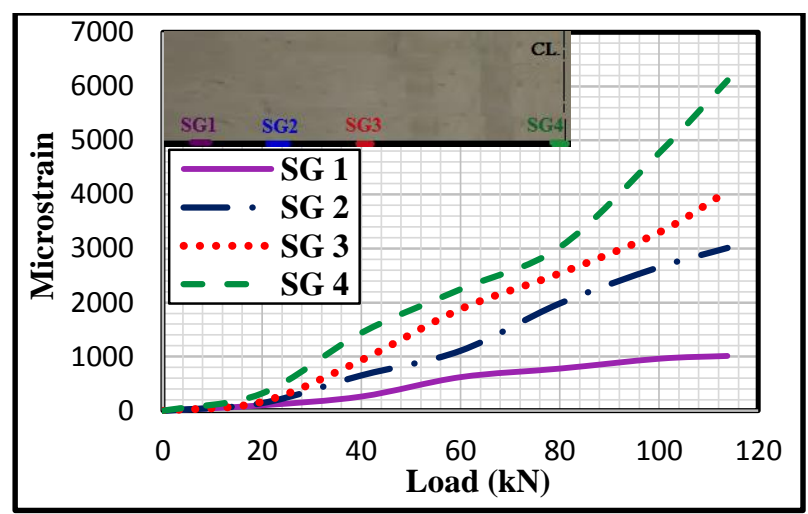

Figure 16: Strain distribution along half of SL beam

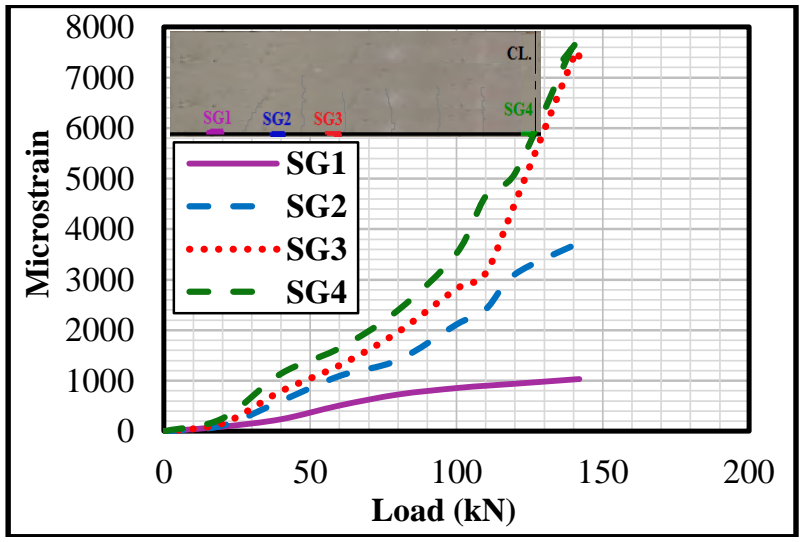

Figure 17: Strain distribution along half of $R L$ beam

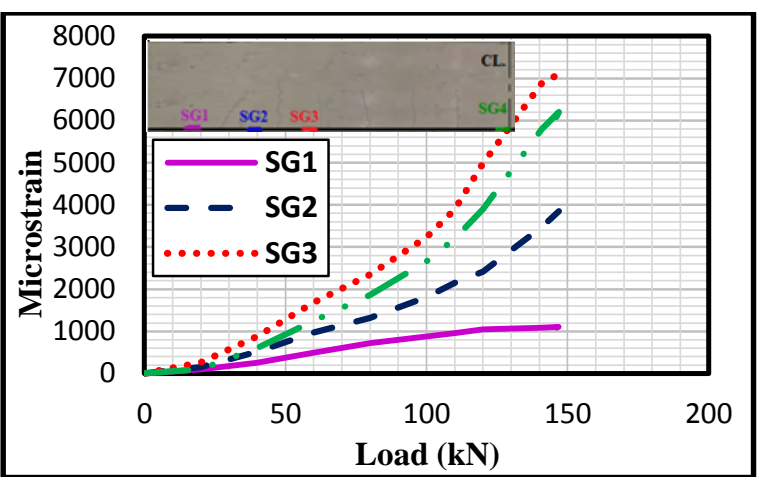

Figure 18: Strain distribution along half of RB beam

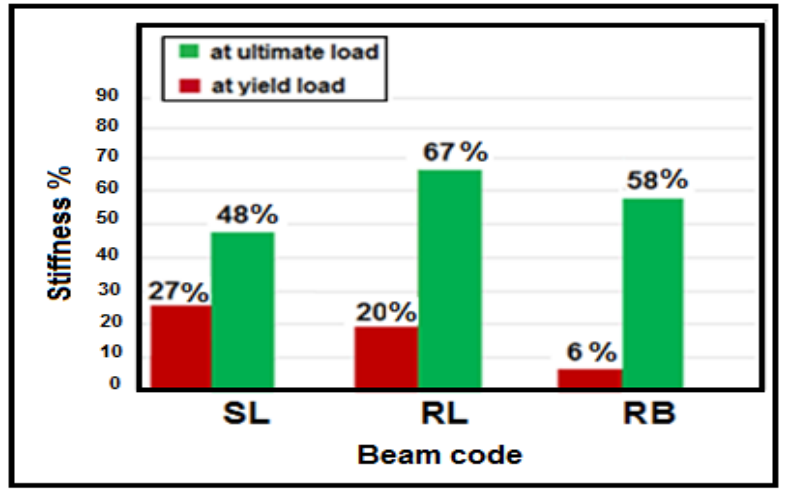

Figure 19: Comparison of stiffness of the strengthened beams at ultimate load and at yielding load of the control beam

Table 7: Summary of ductility index

\begin{tabular}{lllll}
\hline \hline $\begin{array}{l}\text { Beam } \\
\text { Code }\end{array}$ & $\boldsymbol{\mu} \boldsymbol{\Delta} \mathbf{u}$ & $\begin{array}{l}\text { Ratio to } \\
\text { control beam }\end{array}$ & $\boldsymbol{\mu} \boldsymbol{\Delta f}$ & $\begin{array}{l}\text { Ratio to } \\
\text { control } \\
\text { beam }\end{array}$ \\
\hline $\mathrm{C}$ & 3.5 & 1 & 4.6 & 1 \\
$\mathrm{SL}$ & 2.44 & 0.69 & 4.2 & 0.91 \\
$\mathrm{RL}$ & 1.71 & 0.49 & 3.96 & 0.86 \\
$\mathrm{BR}$ & 1.45 & 0.41 & 3.4 & 0.74 \\
\hline
\end{tabular}

\section{Conclusions}

1. The studied beams started cracking at load levels of 56.4, 60.9, 68.4, and $70.5 \mathrm{kN}$ for control beam $\mathrm{C}$, strengthened beams SL, RL, and RB, respectively. Despite the higher failure loads for the strengthened beams, their crack pattern at ultimate load were very similar to the control beam. The favourable influence of CFRP on the cracking behaviour is in agreement with the increased of stiffness in the cracked state of the strengthened beams.

The recorded load-deflection curves clearly show that the three beams strengthened with NSM CFRP showed significant increment in ultimate strength compared to the unstrengthened control beam. The strength increases were 48,42 , and $15 \%$ recorded for the RB beam, RL, and SL beams respectively. 2. Stiffness was minorly effected by NSM-CFRP strips and bars in the pre-cracking stage. In 
contrast, the stiffness and the yielding load of the strengthened beam were increased by the NSMCFRP in the pre-cracking stage the CFRP materials provides constraints to the opening of cracks and reduce the deflection.

3. Beams strengthened with CFRP rough surface strips (RL) experienced higher stiffness than those of specimens strengthened with smooth surface strips (SL) and with CFRP bars (BR) in the post cracking stage, while the SL beam showed higher stiffness at the yielding stage than the RL and BR beams. Increase in stiffness caused lower curvatures, resulting in reduced deflection.

4. All beams exhibited linear response till almost full capacity is attained. The increase in load capacity after steel rebar enters yielding stage and then follows a short plateau stage.

5. NSM-CFRP and RC beams fully behaved as composite beams up to failure. The increase in load with the tensile strain of CFRP up to failure has confirmed full composite action.

6 . The dominant mode of failure for all specimens was flexure failure was failed in. Failure occurred by concrete crushing after yielding of the tension steel reinforcement and debonding of the NSM reinforcement. After yielding of the internal main steel reinforcement, shear cracking initiated at the end of the NSM CFRP bars and the crack width

\section{Acknowledgments}

The authors greatly acknowledge the support of Dr. Riadh Al-Mahaidi who provided the opportunity and helped in the implementation and the financial support. Laboratory assistance on the test from the laboratory technicians of the Smart Structures Laboratory, Swinburne University of Technology is greatly appreciated.

\section{Notation}

The following symbols are used in this paper: CFRP: Carbon Fiber Reinforced Polymer NSM: Near Surface Mounted

RC: Reinforced concrete

Pcr: Cracking load, $\mathrm{kN}$

$\mathrm{Pu}$ : Ultimate load, $\mathrm{kN}$

Py: Yielding load, $\mathrm{kN}$

$\delta \mathrm{c}$ : Deflection of the control beam, $\mathrm{mm}$

$\boldsymbol{\delta}_{\text {cr: }}$ Deflection at cracking, $\mathrm{mm}$

$\delta$ str: Deflection of the strengthened beam, $\mathrm{mm}$ $\delta_{\mathrm{u}}$ Deflection at ultimate, $\mathrm{mm}$

$\Delta f$ : Mid span deflections at failure load, $\mathrm{mm}$ $\Delta u$ : Mid span deflections at ultimate load, $\mathrm{mm}$ $\Delta y$ : Mid span deflections at yield load, $\mathrm{mm}$ $\eta \mathrm{u}$ : load efficiency at $\mathrm{Pu}$ $\eta y:$ load efficiency at Py $\mu \Delta f$ : Displacement ductility index at load at failure $\mu \Delta u$ : Displacement ductility index at ultimate load

\section{References}

[1] American Concrete Institute (ACI), "Guide for the design and construction of externally bonded FRP systems for strengthening concrete structures," ACI 440.2R-08. 2008.

[2] J.A. Barros and A. Fortes, "Flexural strengthening of concrete beams with CFRP laminates bonded into slits," Cement and Concrete Composites, Vol. 27, No. 4, pp.471-480, 2005.

[3] O.L. Gilles Foreta, "Experimental and numerical analysis of RC two-way slabs strengthened with NSM CFRP rods," Construction and Building Materials, Vol. 22, No. 10, pp. 2025-2030, 2008.

[4] F. Ceroni, M. Pecce, A. Bilotta and E. Nigro, "Bond behavior of FRP NSM systems in concrete elements," Composites, Vol. 43: pp. 99-109, 2012.

[5] J. Aidoo, K. Harries and M. Petrou, "Full-scale experimental investigation of repair of reinforced concrete interstate bridge using CFRP materials," Journal of Bridge Engineering, Vol. 11, No. 3, pp. 350358, 2006.

[6] A.N. Porta, G. Manfrediand and E. Cosenza, "Selective upgrade of beam-column joints with composites," Proceedings of the International Conference on FRP Composites in Civil Engineering, Hong Kong, 2001.

[7] S. Hashemi and R. Al-Mahaidi, "Investigation of bond strength and flexural behavior of FRPstrengthened reinforced concrete beams using cementbased adhesives," Australian Journal of Structural Engineering, Vol. 11, No. 2, pp. 129-139, 2010.

[8] Standards Australia (SA), "Methods of testing concrete - Determination of the compressive strength of concrete specimens," Standards Australia. 1012.9, 2014.

[9] Standards Australia, "Methods of testing concrete Determination of indirect tensile strength of concrete cylinders (Brazil or splitting test)," Standard Australia., AS 1012.10, 2014.

[10] Standards Australia (SA), "General purpose and blended cements," Standards Australia. 3972, 2010.

[11] ASTM C 1240-06, "Standard specification for use of silica fume as a mineral admixtures in hydrauliccement concrete, mortar, and grout," Annual Book of ASTM Standards, American Society for Testing and Materials, 2006.

[12] Standards Australia (SA), "'Metallic materials tensile testing at ambient temperature," Standards Australia., 1391, 2007.

[13] American Concrete Institute (ACI), "Guide test methods for fiber-reinforced polymers (FRP) reinforcing or strengthening concrete structures," American Concrete Institute, Farmington Hills, USA, ACI 440.3R-04, 2004.

[14] I.A. Sharaky, L. Torres, J. Comas and C. Barris, "Flexural response of reinforced concrete (RC) beams strengthened with near surface mounted (NSM) fibre 
reinforced polymer (FRP) bars," Composite Structures, Vol. 109, pp. 8-22, 2014.

[15] L. De Lorenzis and J. Teng, "NSM FRP reinforcement: an emerging technique for strengthening structures," Composites Part B: Engineering, Vol. 38, No. 2, pp. 119-143, 2007.

[16] A. Rami, A. Hayder, A. Jamal and K. Adil, "Behavior of reinforced concrete beams strengthened with externally bonded hybrid fiber reinforced polymer systems," Materials and Design, Vol. 53: pp. 972-982, 2014.

[17] H.A. Rasheed, R.R. Harrison, R.J. Peterman, T. Alkhrdaji, "Ductile strengthening using externally bonded and near surface mounted composite systems," Composite Structure, Vol. 92, No. 10 , pp. 2379-2390, 2010 . 